\title{
Ditados populares que abordam tempo e o ensino-aprendizagem de PLE/PL2
}

\author{
Danúsia TORRES-DOS-SANTOS \\ Universidade Federal do Rio de Janeiro \\ dandants@gmail.com
}

Ana Catarina Moraes Ramos NOBRE-DE-MELLO ${ }^{2}$
Universidade Federal do Rio de Janeiro
acnobredemello@globo.com

Maria Emília Barcellos da SILVA

Universidade Federal do Rio de Janeiro

m.emilia@globo.com

\section{Resumo}

O estudo das expressões fixas contribui para uma das grandes demandas do ensino de L2/LE - a aquisição de léxico. $\mathrm{O}$ binômio língua-cultura ganha contornos nítidos no contexto de ensino de uma LE/L2, exigindo do professor reflexão constante a respeito dos tópicos que delineiam a identidade linguístico-cultural da língua-alvo. Partindo-se do pressuposto de que tempo e cultura são indissociáveis, o professor de PLE/PL2 deve estar preparado para, em sala de aula, abordar a concepção de tempo do brasileiro. Este trabalho, apoiando-se na noção de linguagem do tempo (HALL, 1996), busca identificar aspectos da concepção brasileira de tempo. As chamadas expressões fixas apresentam-se das mais variadas maneiras no acervo fraseológico da língua, sendo difícil manter as fronteiras teóricas entre seus tipos. Considerando-se a definição de ditado proposta por Silva (1999, p. 14-15), selecionaram-se ditados populares concernentes ao tempo usados no Brasil. Constatou-se

\footnotetext{
Doutora em Estudos da Linguagem e professora do Departamento de Letras Vernáculas/ UFRJ.

Mestre em Linguística Aplicada e professora do Departamento de Letras Vernáculas/ UFRJ.

3 Doutora em Língua Portuguesa e professora do Departamento de Letras Vernáculas/ UFRJ.
} 
que há, na sabedoria popular, pelo menos dois tipos de expressões que abordam o tempo: a) expressões relacionadas ao conceito de clock time $e^{4} \mathrm{e}$ b) expressões relacionadas ao conceito de event time (LEVINE, 1997). Pretende-se, assim, que este estudo possa auxiliar o professor de PLE/PL2 a abordar esse tema em sala de aula.

Palavras-chave: português língua estrangeira; tempo; expressões fixas; ditados populares; cultura

\begin{abstract}
The study of fixed expressions contributes to a significant demand of L2/SL teaching, the lexicon acquisition. The binomial language/ culture gained a clear shape in the context of L2/SL teaching, so as to require the teacher to reflect constantly on the topics that outline the linguistic and cultural identity of the target language. Based on the assumption that time and culture are inseparable, the PFL/ PL2 (Portuguese as a Foreign/ Second Language) teacher has to be prepared to address the Brazilian concept of time. Relying on the notion of time language (HALL, 1996), this study seeks to identify aspects of the Brazilian temporal language. As fixed expressions have different types, it is often difficult to maintain theoretical boundaries among them. Considering Silva's definition of proverb (1999:14-15), some Brazilian popular sayings concerning time were selected. It was found that popular wisdom has at least two types of expressions that refer to time: those related to the concepts of clock time and the ones linked to the concepts of event time (LEVINE, 1997). It is intended therefore that this study may assist the PFL/PL2 teacher in addressing this issue.
\end{abstract}

Keywords: Portuguese as a second/foreign language; time; fixed expressions; proverbs; culture.

\title{
1. Sobre a ideia de tempo
}

O estudo das expressões fixas relacionadas ao tempo pode servir de chave para se entrever as nuances de um conceito que ganha peculiaridades

4 Clock time - tempo cronológico, preciso, invariável.

5 Event time - tempo evento, impreciso, variável de acordo com a situação. 
importantes no contexto brasileiro. Percebe-se que o tema é bastante pertinente para o ensino de PLE/PL2, dado que, com frequência, surgem durante as aulas questionamentos em torno da temporalidade brasileira. Deve-se, assim, buscar conhecer melhor o percurso teórico desse conceito, problematizando-o para além de sua prosaica correspondência com o objeto relógio.

Com o propósito de melhor compreender a concepção de tempo dos brasileiros, principalmente no que diz respeito à gestão e ao valor do tempo, realizou-se, entre 2006 e 2011, em sites dedicados ao registro de provérbios/ ditos populares, um levantamento, não exaustivo, de expressões de tempo. Além disso, com o intuito de complementar esses dados, realizou-se um mapeamento nos sites dos jornais Extra e $O$ Globo a fim de detectar alguns exemplos de uso dessas expressões.

Desde sempre a ideia de tempo tem sido objeto de reflexão e estudo nas mais diversas perspectivas, da física à filosófica, passando pela linguística, pela religiosa, pela antropológica e, sem dúvida, pela literária.

Dentre os estudos brasileiros que seguem uma perspectiva literária, destaca-se o de Benedito Nunes, O tempo na narrativa (1995), no qual o autor analisa a questão do tempo em diversas obras literárias. No capítulo 2, "Do tempo real ao tempo imaginário", é feita uma revisão dos estudos sobre o tempo, seguindo uma perspectiva histórica e interdisciplinar que auxilia bastante a quem se inicia no estudo do assunto. Nunes lembra os relógios de sol e as ampulhetas para, então, passar do tempo absoluto de Newton à concepção plural do tempo relativo de Einstein, destacando que a interpretação do conceito de tempo tem sido influenciada pelos estudos da Física:

Newton, no século XVII, distinguiu o tempo relativo, "aparente e vulgar", do tempo absoluto, "verdadeiro e matemático", comparável a um relógio universal único, que funcionasse uniformemente, em correlação com o espaço, ao qual também atribuiu caráter absoluto. No século XX, Einstein relativizou o tempo físico, levando em conta acontecimentos simultâneos - aqueles que ocorrem ao mesmo 
tempo. Em lugar do relógio universal e único de Newton, admitiu tantos relógios quantos fossem os sistemas de relação entre eventos e cada ponto demarcável do Universo, e, portanto, em cada porção do espaço [...]. Einstein formulou a idéia de interdependência do espaço e do tempo [...] entre dois eventos simultâneos não existe uma relação espacial absoluta ou uma relação temporal absoluta (NUNES, 1995, p. 18).

Ligado ao tempo físico, surge o tempo cronológico, socialmente organizado por meio de calendários, o "tempo público". Esse conceito de tempo pode apresentar outros recortes ligados a fenômenos socioculturais: o litúrgico (regula ritos e celebrações religiosas), o político (organiza a periodicidade dos eventos cívicos) e o histórico (descreve períodos longos ou curtos, de acordo com a singularidade ou a complexidade dos acontecimentos considerados).

Há ainda o tempo linguístico, tempo do discurso, baseado na intersubjetividade da comunicação, funcionando o "presente da enunciação como eixo temporal com base no qual os eventos se ordenam" (NUNES, 1995, p. 22). Pode-se discorrer sobre o que está acontecendo, o que já aconteceu ou o que vai acontecer, segundo o momento da fala, referencial temporal da linguagem.

A etnografia de Evans-Pritchard, Os nuer (1978), nome de uma tribo africana situada ao sul do Sudão, visitada pelo antropólogo britânico em 1930, descreve diversos aspectos da vida nuer, dentre eles, tempo e espaço. Destaca-se um trecho da descrição feita por ele da relação dos nuer com o tempo que ainda hoje pode causar certo espanto por descortinar uma concepção de tempo bastante diversa daquela existente na maioria dos países ocidentais:

Os nuer não possuem uma expressão equivalente ao "tempo" de nossa língua e, portanto, não podem, como nós, falar do tempo como se fosse algo concreto, que passa, pode ser perdido, pode ser economizado e assim por diante. Não creio que eles tenham a mesma sensação de lutar contra o tempo ou de terem de coordenar as atividades com 
uma passagem abstrata do tempo, porque seus pontos de referência são principalmente as próprias atividades sociais, que, em geral, têm caráter de lazer. Os acontecimentos seguem uma ordem lógica, mas não são controlados por um sistema abstrato, não havendo pontos de referência autônomos aos quais as atividades devem se conformar com precisão (EVANS-PRITCHARD, 1978, p. 116).

Estudos como o de Evans-Pritchard comprovam a relação entre a concepção humana de tempo e o contexto cultural, além de abrirem novas perspectivas para o estudo do tempo e do espaço. Considera-se, desse modo, o tempo como dimensão cultural, como um traço distintivo que pode proporcionar uma melhor compreensão de uma dada cultura, posto que "o indivíduo, ao crescer, aprende a interpretar os sinais temporais usados em sua sociedade e a orientar sua conduta em função deles" (ELIAS, 1998, p. 15).

Partindo-se do pressuposto de que a experiência social e cultural do ser humano, de algum modo, interfere na sua concepção de tempo, ressalta-se a relevância do aprendizado da "linguagem do tempo" de outras culturas com as quais se pretende estabelecer algum tipo de contato:

Cada cultura tem os seus próprios quadros temporais no interior dos quais funcionam modelos que lhe são específicos: o que constitui um fator de complicação das relações interculturais. Assim, para poder efetivamente comunicar no estrangeiro, é tão necessário conhecer a linguagem do tempo como a linguagem falada no país em que nos encontramos (HALL, 1996, p. 12).

Para Hall (1996, p. 13), “o tempo e a cultura são indissociáveis em certas circunstâncias”, embora afirme existirem pesquisadores que levam o conceito de tempo absoluto newtoniano tão a sério que deixam de considerar estudos como o de Evans-Pritchard sobre os nuer. Ao comprovarem a relação entre a concepção humana de tempo e o contexto cultural, ou seja, não só a relatividade do tempo, mas seu aspecto múltiplo, plural, estudos como o realizado por Evans-Pritchard colaboraram para o estabelecimento de novos paradigmas para o estudo do tempo fora do âmbito da Física. 
Tendo como referência básica a Grã-Bretanha, Thompson, em seu Costumes em comum: estudos sobre a cultura popular tradicional (1998), não deixa de fazer referência a outras culturas. Além do tempo baseado na sucessão de tarefas pastoris dos nuer, Thompson (1998, p. 269-270) lembra outros exemplos de medição cultural do tempo: tempo de "cozimento do arroz" (meia hora), tempo de "fritura de um gafanhoto" (um momento), utilizados em Madagáscar; tempo que leva o "milho para assar"(15 minutos), usado em Cross River, no sudeste da Nigéria. São lembrados, ainda, dois exemplos do Chile, em que o tempo de cozimento de um ovo podia ser medido por "uma Ave-Maria rezada em voz alta" e a duração de um terremoto foi estimado em dois credos, segundo descrição datada de 1647.

Com base nas categorias temporais propostas por Hall (1996, p. 27) em sua Carta do tempo, é objeto desta pesquisa o microtempo, ou, mais especificamente, alguns aspectos do microtempo da cultura brasileira. Sendo um produto do nível primário da cultura, o microtempo guarda as regras inconscientes ou semiconscientes partilhadas por indivíduos de um mesmo grupo social no que diz respeito à concepção do tempo. Monocronia, que consiste em "prestar atenção e fazer uma coisa de cada vez", e policronia, que consiste em "estar envolvido com muitas coisas de uma vez", são exemplos de aspectos do microtempo. Segundo Hall (1996, p. 57), esses dois sistemas são como azeite e água, não se misturam, e “cada um tem suas vantagens e seus inconvenientes”. Em sua explanação sobre a monocronia e a policronia, Hall (1996, p. 55-65) opõe Europa do Norte e Estados Unidos, vinculados ao tempo monocrônico, e Mediterrâneo e à América Latina, vinculados ao tempo policrônico.

Enquanto Harrison (1983) e Oliveira (2001) fazem referência direta ao tempo policrônico brasileiro, o psicólogo social Levine (1997, p. 97) vincula o tempo monocrônico e o tempo-relógio a sociedades industrializadas e "orientadas para a realização", como os Estados Unidos, e o tempo policrônico e o tempo-evento a países do "terceiro mundo".

Segundo Stewart e Bennett (1991, p. 125), o afastamento de uma concepção cíclica do tempo, relacionada, entre outras coisas, às mudanças 
das estações climáticas, em direção a uma concepção linear do tempo, levou à ideia americana de progresso como desenvolvimento contínuo, de um estágio primitivo a um estágio em que, por exemplo, as adversidades da natureza seriam controladas pelos recursos tecnológicos desenvolvidos pelo homem.

Considerando a ideia de controle do tempo igual à eficiência e à produtividade, surgem, em 1980, em São Paulo, no Rio e em estados da Região Sul do Brasil os cursos de Administração do Tempo, voltados para o mundo dos negócios. Segundo Bethlem (1999, p. 41), o tempo no Brasil não é importante: "As pessoas são impontuais profissionalmente e 'desligadas do tempo' socialmente [...]”.

Em crônica intitulada "O tempo do desenvolvimento", Castro (2004) analisa a gestão do tempo no Brasil em diferentes contextos profissionais:

Na Esplanada dos Ministérios, em Brasília, a conferência marcada para as 10 horas começará em horas diferentes, dependendo do ministério. No Itamaraty, começa na hora. $\mathrm{Na}$ área econômica, cabem alguns minutos de tolerância. $\mathrm{Na}$ área social, estão todos muito ocupados, e meia hora de atraso não é incomum. Curioso, os ministérios mais eficazes são aqueles em que as reuniões começam na hora. Quem marca com o consertador do computador, da televisão, da pia ou da máquina de lavar terá uma surpresa se a criatura vier - e mais ainda se chegar na hora marcada. Já nas empresas modernas, a chance de andar no horário é bem maior.

Shirts (2004), na crônica "A diferença entre a noite e o dia", comenta a Campaña contra la impuntualidad. Essa campanha teria como objetivo nortear a informalidade com que os equatorianos encaram o relógio e, para Shirts, isso seria indício de que os equatorianos querem fazer parte do mundo globalizado, desejam disciplinar o uso que fazem do tempo.

A geography of time (1997), de Levine, impõe-se como leitura necessária para pesquisas sobre o tempo e a pontualidade na cultura brasileira. $\mathrm{O}$ autor relata as dificuldades que teve para se adaptar ao tempo brasileiro e que o fizeram experimentar um verdadeiro choque cultural: 
Durante meu ano no Brasil, fiquei repetidamente confuso, frustrado, fascinado e obcecado pelos costumes e idéias de tempo social que os brasileiros "colocaram no meu caminho". As razões pelas quais as regras de pontualidade dos brasileiros me confundiram tanto, logo se tornaram evidentes, elas estão inseparavelmente entrelaçadas com os valores culturais. E quando nós entramos na teia da cultura, as respostas não vêm nem simplesmente nem claramente. As crenças culturais são como o ar que respiramos, então aceitamos que elas sejam raramente discutidas ou até mesmo pronunciadas. Mas há frequentemente uma rápida reação quando essas regras não escritas são violadas. Um inesperado forasteiro como eu pode andar em um campo minado cultural ${ }^{6}$ (LEVINE, 1997, p. XV).

Levine (1997, p. XVI) faz um estudo comparativo de três aspectos da concepção de tempo em diversos países: a velocidade do andar, a velocidade do trabalho e a precisão dos relógios públicos, buscando, assim, meios para melhor compreender as crenças e as regras da pontualidade brasileira. Segundo o estudioso, a pesquisa trouxe mais questões que respostas, pois "há drásticas diferenças em todos os níveis: de cultura para cultura, de cidade para cidade, e de vizinho para vizinho. E, acima de tudo, eu aprendi, o tempo do relógio apenas começa a contar a história”. ${ }^{7}$

\section{As expressões fixas e o ensino de línguas estrangeiras}

Conforme demonstram os estudos considerados neste trabalho, a questão do tempo é complexa e multidisciplinar; além de ainda carecer, no que diz respeito à cultura brasileira, da descrição de muitos de seus aspectos. Para a realização de uma pesquisa sobre o conceito de tempo na

6 During my year in Brazil, I was repeatedly bewildered, frustrated, fascinated, and obsessed by the customs and ideas of social time that Brazilians sent my way. The reason that Brazilians' rules of punctuality so confused me, it soon become apparent, was that they are inseparably intertwined with cultural values. And when we enter the web of culture, answers come neither simply nor cleanly. Cultural beliefs are like the air we breathe so taken for granted that they are rarely discussed or even articulated. But there is often a volatile reaction when these unwritten rules are violated. Unsuspecting outsiders like myself can walk into a cultural minefield.

7 There are drastic differences on every level: from culture to culture, city to city, and from neighbor to neighbor. And most of all, I have learned, the time on the clock only begins to tell the story. 
cultura brasileira, torna-se necessário rever padrões, convicções e crenças do que possa ser definido como tempo e como tempo brasileiro. As expressões fixas relacionadas ao tempo utilizadas no Brasil parecem ser um importante elemento nessa trajetória investigativa, pois sintetizam muito do valor do tempo compartilhado entre os brasileiros.

De modo geral, nas últimas décadas, a abordagem comunicativa tem norteado o ensino de LE/L2. Sendo assim, professores e pesquisadores delimitam, habitualmente, três competências gerais relacionadas ao ensino-aprendizagem de L2/LE: competências linguísticas; competências sociolinguísticas e competências pragmáticas. As competências linguísticas englobam o das formas que possibilitam a elaboração de mensagens que cumprem os propósitos do usuário da língua. A competência lexical é uma dessas competências e envolve o conhecimento e a capacidade de utilização do vocabulário de uma língua.

Dentre os muitos aspectos do acervo lexical da língua portuguesa utilizada no Brasil ainda à espera de descrição, optou-se pelo estudo das expressões fixas, mais especificamente, de alguns dos ditados populares relacionados à concepção de tempo. Embora os ditados sejam constituídos por um número variável de palavras, são aprendidos e utilizados como conjunto, fato que os caracteriza como expressões fixas.

A aquisição, ou ao menos a compreensão das expressões fixas, colaboraria, assim, para sanar a necessidade de o aprendiz de língua estrangeira superar o estágio de "falante ingênuo", aprendendo o jeito peculiar de dizer as coisas da comunidade linguística-alvo, ou seja, "o jeito que a gente diz" (TAGNIN, 1989, p. 10). Esse jeito peculiar de dizer as coisas se distribui das mais variadas maneiras na estrutura da língua. As chamadas expressões fixas dividemse em alguns tipos que, muitas vezes, misturam-se, sendo frequentemente difícil manter as fronteiras teóricas entre eles. Tagnin, por exemplo, centra seu estudo na delimitação de expressões idiomáticas e convencionais:

[...] há expressões que são convencionais por estarem intimamente ligadas a um fato social e há outras em que o que é convencional é sua forma. Por exemplo, Feliz Natal é uma expressão convencional 
social, pois está ligada à comemoração do Natal, enquanto mundos e fundos é uma expressão convencional devido a sua forma, isto é, convencionalizou-se combinar os dois vocábulos mundos e fundos - e não universos e profundidades, por exemplo - unidos pela conjunção e. E convencionou-se também ser esta a ordem em que devem aparecer, jamais fundos e mundos. Outro exemplo que não admite alteração de ordem é doce ilusão, pois ilusão doce perderia o tom irônico da expressão anterior (TAGNIN, 1989, p. 13).

Vale ressaltar que a definição de idiomático adotada por Tagnin, como não transparente, opaco, se opõe àquela tradicionalmente adotada, nas literaturas nacional e estrangeira, de "vernáculo, próprio da língua". Linguistas o definem como estruturas cujo significado é não composicional, isto é, o significado da expressão completa não é perceptível a partir do significado dos seus componentes, é visto como uma estrutura idiomática com graus de idiomaticidade:

[...] a idiomaticidade é uma questão de grau. Assim, podemos talvez analisar as expressões idiomáticas numa escala de idiomaticidade, colocando, na parte mais baixa dessa escala, as expressões menos idiomáticas e, na parte mais alta, as totalmente idiomáticas. Por menos idiomáticas entendemos quer as expressões em que apenas um ou alguns de seus elementos são idiomáticos, quer as expressões metafóricas cuja imagem seja de fácil decodificação. Por totalmente idiomáticas entendemos as expressões em que nenhum de seus constituintes contribui com seu significado para o significado total da expressão (TAGNIN, 1989, p. 47).

Analisando as expressões segundo os graus de idiomaticidade, a autora sugere uma distinção entre as metafóricas e as idiomáticas propriamente ditas. Quando há uma ligação entre a expressão e a imagem por ela sugerida, trata-se de uma expressão metafórica; quando essa ligação se torna totalmente opaca e não pode mais ser nem parcialmente recuperada, trata-se de uma expressão idiomática propriamente dita.

Tem-se de ter em vista que toda expressão idiomática é um convite à formação de uma imagem mental recortada do universo cultural do 
usuário. A relação entre a expressão idiomática e a imagem a que ela se refere, por vezes, perde-se no tempo e, hoje, passa a ser apenas uma alusão. Essa constatação evidencia que os idiomatismos portam um sentido tanto material quanto sugestivo para quem os profere ou escuta; inegavelmente o apelo mais frequente é o grande instigador da imagem.

Sendo assim, traduzir literalmente as expressões idiomáticas mais banais não raro cria situações de inesperados mal entendidos. As locuções idiomáticas ou frases feitas aproximam-se dos provérbios, ditos que sumarizam as situações mais prosaicas do falante. Os ditos correntes em outros países talvez configurem o fato de os idiomatismos se constituírem em verdadeiras muralhas entre os povos: podem-se conhecer as palavras isoladamente, mas ignorar o que o dito significa.

Com relação ao fato de as partes das expressões colaborarem ou não para a apreensão do significado e em uma maior ou menor proporção, o modelo híbrido apresentado por Titone e Connine (1999) é bastante esclarecedor. As autoras analisam a abordagem não composicional, que considera as expressões idiomáticas palavras longas, cujos componentes não influenciam nem direcionam a compreensão dessas expressões; e a abordagem composicional, que considera importante para a interpretação das expressões o significado individual de seus componentes. Segundo essa proposta, as expressões idiomáticas funcionam, ao mesmo tempo, como "sequências de palavras semanticamente arbitrárias" e como "frases compostas" (TITONE; CONNINE, 1999, p. 1656).

Cabe lembrar ainda o conceito de expressão idiomática apresentado por Ortíz Alvarez (1998, p. 103): "A nosso ver uma expressão idiomática é uma combinação (sintagma) metafórica que se cristalizou pelo uso e pela frequência de emprego (passando do individual para o social) numa determinada língua apoiada na sua tradição cultural". Portanto, uma pesquisa sobre expressões idiomáticas deverá observar sempre esses dois

8 "We support a hibrid view of idiom representation and processing that simultaneously treats idioms as noncompositional and compositional word sequences. That is, idiomatic meanings are both directly retrieved and literally analyzed during comprehension." 
estágios pelos quais elas passam: o processo de cristalização do significado e a frequência (retirar o trema) de uso pelos falantes da língua em questão.

Para se desenvolver um trabalho sobre ditados populares brasileiros, torna-se necessário percorrer o caminho da definição do termo expressão fixa. Silva (1999, p. 12) aborda esse termo aliando-o ao conceito de discurso repetido e lembrando ainda outro, o de expressões pré-fabricadas: “Consideremos 'discurso repetido' qualquer tipo de expressão cujos elementos não sejam substituídos ou recambiáveis segundo as regras atuais da língua, importando, principalmente, o seu conceito de expressões préfabricadas". Em seu estudo, o autor classifica as unidades do discurso repetido em dois níveis linguísticos distintos:

a) [...] nível lingüístico do texto: todas as que correspondem a uma unidade com sentido completo, em qualquer nível de complexidade. Podem corresponder a uma oração ou até a uma unidade mais complexa: o provérbio, o ditado, o refrão, o adágio, a máxima, a sentença, o aforismo, [...] b) nível lingüístico do sintagma: são todas as que estão abaixo do nível da oração, unidades combináveis com sintagmas e com simples palavras, cuja interpretação se faz ao nível do léxico. Do ponto de vista do significante, são unidades que funcionam como unidades léxicas, pouco importando o número e a complexidade dos elementos constituintes discerníveis (SILVA, 1999, p. 13).

O autor dá prosseguimento à sua exposição lembrando que o discurso repetido abrange tudo que tradicionalmente está fixado como expressão, giro, modismo, frase ou locução (SILVA, 1999, p. 13). As frases feitas, ainda segundo o autor, não têm sentido completo, funcionam como um sintagma, possuem forma e sentido fossilizados, tornando-se especialmente dependentes da cadeia da fala e do contexto. Em sentido amplo, pode-se dizer que o termo engloba todos os tipos de expressões fixas ou de discurso repetido.

Ao longo de seus ensaios, é apontada a falta de "precisão no uso desses termos", pois a "terminologia demasiado flutuante, ora demasiado restrita, ora extremamente ampla, confunde mais que esclarece, e torna difícil uma 
fundamentação convincente de uma classificação objetiva" (SILVA, 1999, p.18). Tal desconforto é frequentemente externado pelos pesquisadores que se dedicam a esse assunto, seja qual for o recorte do objeto a ser pesquisado.

A descrição apresentada por Pontes (1992) possibilita uma melhor compreensão das expressões linguísticas relacionadas a cada uma dessas noções. Pontes observa que muitas das expressões de tempo são construídas com base em categorias que indicam espaço. Analisa, então, como esse processo se dá, calcado na descrição do uso de preposições, advérbios, locuções e pronomes demonstrativos e relativos, além dos advérbios de tempo propriamente ditos: amanhã, hoje, agora, ontem, sempre, nunca, entre outros. Segundo Pontes, o conceito de tempo, em língua portuguesa, é espacial, é uma "metáfora espacial", sendo o tempo concebido linearmente e tendo como referência o momento da enunciação.

\section{As expressões de tempo usadas no Brasil e o ensino de PLE/PL2}

Neste estudo, ao contrário de Pontes, não trabalhamos com a noção de tempo linguístico, mas com uma concepção social de tempo registrada em expressões no uso corrente da língua portuguesa falada no Brasil. Sendo assim, para o estudo da noção de tempo vinculada à língua há outro caminho, paralelo ao trilhado por Pontes, em que o entrelaçamento línguacultura se torna ainda mais nítido - o estudo dos ditos populares.

Se, por um lado, o estudo das expressões fixas de uma língua colabora para um conhecimento mais amplo de seu acervo fraseológico, contribuindo para melhor elucidação de uma das grandes demandas do ensino de L2/LE, a aquisição de léxico, ou mais especificamente a aquisição das expressões fixas da língua, por outro, permite ao aprendiz de L2/LE o acesso ao "patrimônio lingüístico [...] onde se manifesta a visão de mundo de uma determinada cultura, os seus costumes populares e tradições que evoluem no tempo a partir do contato com outras culturas" (ORTÍZ ALVAREZ, 1998, p. 102).

Considerando que o ditado é uma construção direta e denotativa, "diz respeito a setores precisos de atividade e a grupos específicos e fica 
na simples observação e constatação dos fatos, sem julgá-los" (SILVA, 1999, p. 14-15), selecionaram-se ditados populares usados no Brasil que abordam a questão do tempo. Essas expressões foram resultado de uma busca na internet em obras como, Dicionário brasileiro de ditados populares (PERGUNTAS CRETINAS, 2006), Como vovó dizia: a sabedoria popular dos provérbios (JANGADA BRASIL,1998), Adágio brasileiro (dito popular) (PORTAL BRASIL, 2001) e Anexins em contramão (XIDIEH, 1999).

Com base nas expressões levantadas, pode-se dizer que há, na sabedoria popular brasileira, pelo menos dois tipos de expressões que abordam o tempo:

1)

Deus ajuda a quem cedo madruga.

Não se deixa para amanhã o que se pode fazer hoje.

O tempo voa/foge.

Madruga e verás, trabalha e terás.

Tempo e maré não esperam por ninguém.

Tempo perdido não se recupera.

O tempo não volta atrás.

Tarde dar é o mesmo que negar.

Quem espera desespera.

2)

A pressa é inimiga da perfeição.

Devagar se vai ao longe.

Antes tarde do que nunca.

Ri melhor quem ri por último.

Os últimos serão os primeiros.

Quem espera sempre alcança.

Nada como um dia após o outro.

Dê tempo ao tempo.

O futuro a Deus pertence. 

Apressado come cru (e passa mal).
Mais vale quem Deus ajuda do que quem (muito) cedo madruga.
O que se não faz no dia da romaria, faz-se no outro dia.
Tempo é remédio.
Tudo na vida requer tempo e medida.

As expressões do primeiro conjunto podem ser relacionadas às concepções de tempo digital, clock time (LEVINE, 1997) ou monochronic time (HALL, 1996), em que a hora e o tempo são considerados de modo absoluto, isolado, preciso, rígido, fixo. As expressões do segundo conjunto, inversamente, estão relacionadas às concepções de tempo analógico, event time (LEVINE, 1997) ou polychronic time (HALL, 1996), que abordam hora e tempo de modo relativo, relacional, impreciso, flexível, maleável.

Se o primeiro elenco lembra a implacabilidade do tempo, a premência de atitudes e decisões, as do segundo grupo consolam e dão esperança. Contradizendo toda aquela pressa das primeiras expressões, sinalizam para a possibilidade de outra relação com o tempo. A seleção aqui considerada de ditados populares parece sinalizar para a convivência pacífica, na língua-cultura brasileira, tanto com as expressões do primeiro elenco quanto com as do segundo, ou ainda, pode-se correr o risco de dizer, melhor com as do segundo do que com as do primeiro. Esse fato pode ser interpretado como indício de uma flutuação entre pelo menos dois padrões de gestão do tempo na língua-cultura brasileira e, a depender da situação, até mesmo da possibilidade de certa inversão ou questionamento do valor de algum ditado, como se pode constatar na seguinte passagem do Jornal Extra On Line:

Trânsito de SP já não ajuda quem cedo madruga

O ditado "Deus ajuda quem cedo madruga" já não vale para os motoristas da capital paulista. Um levantamento da Companhia de Engenharia de Tráfego (CET) revelou que a cidade teve um aumento nos congestionamentos no início das manhãs, às $7 \mathrm{~h}$, em janeiro e fevereiro. (NOVAES, 2009) 
Essa possibilidade de questionamento ou de relativização do valor do ditado, conforme observado nos dados, denota certa flexibilidade em relação ao uso dessas expressões. Estudiosos da cultura brasileira apontam a flexibilidade e a ambiguidade como traços marcantes dessa cultura. DaMatta (1993, p. 146), por exemplo, ao referir-se à ambiguidade brasileira, afirma que "[...] não se trata apenas de mera contradição, mas de uma lógica que salienta o ambíguo e o intermediário”. Barbiero (1999, p. 11), por sua vez, dá um passo adiante e considera "a ambiguidade um instrumento imprescindível para se estudar o Brasil".

Seguindo essa linha, Barbosa lembra que, na sociedade brasileira, há uma superposição dos "valores da modernidade" e dos valores tradicionais, "criando um descompasso entre norma e prática social” (BARBOSA, 1992, p. 86) e provocando a condição multivalorativa da sociedade brasileira. Essa "condição multivalorativa" permite que o descompasso entre o velho e o novo seja vivenciado não necessariamente por meio do conflito, mas como forma de perene aprendizado do valor das diferenças.

A concepção linear do tempo ligada à ideia de progresso teve respaldo no evolucionismo, teoria antropológica que partia do pressuposto de que havia uma escala linear de desenvolvimento e, de acordo com o posicionamento nessa escala, as sociedades poderiam ser classificadas como primitivas ou desenvolvidas (CASTRO, 2005).

É fato, porém, que além de o progresso tecnológico por si só não garantir o controle das "adversidades da natureza" muitas vezes colabora, mesmo que indiretamente, para que essas adversidades aconteçam. Muitas delas ocorrem como consequência do desrespeito pelo meio ambiente devido à priorização total do desenvolvimento industrial-tecnológico.

Levando-se em consideração tais aspectos, explicita-se a inconsistência do pensamento evolucionista, que frequentemente norteia o senso comum e poderia sugerir que o Brasil não é um país evoluído por não seguir rigidamente o padrão horário de países considerados desenvolvidos, "modernos".

Pretende-se, com esse estudo, promover uma reflexão a respeito dos pressupostos evolucionistas que possibilite a compreensão de um modo de 
ser e viver que não seja obrigatoriamente classificado como primitivo/antigo em oposição a civilizado/moderno. A concepção do tempo como recurso a ser controlado e explorado é partilhada por países como França e Japão, mas há países em que "o tempo é usado para orientação, mais do que algo a ser dominado, a vida é menos apressada. Seria o caso da Grã-Bretanha e da Suécia”, segundo Bethlem (1999, p. 41). Explicita-se, assim, uma clara variação da concepção de tempo, mesmo entre os países ditos desenvolvidos.

Os estudiosos considerados neste estudo, ao compararem as concepções de tempo nas diferentes culturas, são unânimes quanto à necessidade de reconhecimento e de respeito pelas diversas temporalidades. Além disso, destacam os problemas advindos da concepção time is money. Elias (1998, p. 157) declara que "a pressão do tempo, em sua qualidade de aspecto do código social, gera, em sua forma atual, problemas que ainda estão à espera de uma solução”.

Segundo Levine (1997, p. 187), todas as culturas têm algo a aprender com outras concepções de tempo, e os diferentes ritmos de vida nada mais são do que modos diferentes de se viver, cada um deles com seus pontos positivos e negativos. Sendo assim, defende Levine (1997, p. 219), não haveria um ritmo de vida melhor do que outro, mas ritmos mais apropriados a determinadas situações ou objetivos. Entre a premência no desenvolvimento de determinada tarefa e o lazer coloca-se, inevitavelmente, a necessidade de alternância de ritmos. $\mathrm{O}$ deslocamento equivocado do ritmo A para uma situação que requer o ritmo $\mathrm{B}$ redundaria em falha de propósitos.

Preocupação semelhante é externada por Thompson (1998, p. 302) ao discutir o "problema do lazer", que, após a saturação do tempo é dinheiro trazido pela Revolução Industrial, as pessoas terão de reaprender algumas das artes de viver:

Nasceria então uma nova dialética em que algumas das antigas energias e disciplinas migrariam para as nações em processo de civilização recente, enquanto as antigas nações industrializadas procuram redescobrir modos de experiência esquecidos antes do início da história escrita. (THOMPSON, 1998, p. 302). 
Se, por um lado, concordamos com a nova dialética apontada por Thompson, por outro, não podemos deixar de questionar seus termos. Desempenhariam as "nações em processo de industrialização recente" meramente o papel de receptoras de "antigas energias e disciplinas" ou poderiam ser mais atuantes na construção de um intercâmbio de experiências relacionadas ao tempo? Considera-se mais pertinente outra afirmação do estudioso que, sem fazer referência a nações, destaca a necessidade de uma nova síntese que combine elementos do velho e do novo:

[...] descobrindo um imaginário que não se baseie nas estações, nem no mercado, mas nas necessidades humanas. A pontualidade no horário de trabalho expressaria respeito pelos colegas. E passar o tempo à toa seria comportamento culturalmente aceito (THOMPSON, 1998, p. 303).

Sendo assim, a concepção brasileira de tempo parece ter muito a colaborar para a descoberta de novos parâmetros temporais, em que temporelógio e tempo-evento e rapidez e vagar não seriam excludentes, e sua alternância, de acordo com as situações, sinalizaria capacidade de adequação social. Essa possibilidade de alternância entre os dois sistemas é o que Levine chama de middle time (1997, p. 211), padrão temporal alternativo ao time is money e que possibilitaria formas renovadas de interação social e com o meio ambiente.

No que diz respeito ao ensino das expressões fixas, faz-se necessário lembrar a distinção entre compreensão e produção. $O$ aprendiz deve ser estimulado a ampliar sua capacidade de compreensão dessas expressões e, posteriormente, incentivado a experimentar utilizá-las. Desse modo, se a compreensão dos ditados populares auxilia o entendimento da peculiar concepção de tempo na cultura brasileira, seu uso pelos aprendizes de PLE/ PL2 pode servir como demonstração do grau de sofisticação de diversas competências (lexical, sociolinguística, intercultural).

Conhecer essas expressões em uso no contexto brasileiro permite, portanto, que os aprendizes tenham acesso ao patrimônio linguístico “[...] 
onde se manifesta a visão de mundo de uma determinada cultura [...]" (ORTÍZ ALVAREZ, 1998, p. 102). O acesso à visão de mundo veiculada pelos ditados populares favorece o reconhecimento de outros modos de existência e o surgimento de reflexões interculturais que, no final das contas, é ou deveria ser o objetivo do ensino de aspectos da cultura-alvo.

\section{Referências}

BARBIERO, Alan. Brasis ou Brasil?:reflexões para uma sociologia da ambiguidade brasileira. Universidade E̋ Sociedade, v. 9, n. 20, Brasília, 1999. BARBOSA, Lívia. O jeitinho brasileiro. Rio de Janeiro: Campus, 1992.

BETHLEM, Agricola. S. Gestão de negócios: uma abordagem brasileira. Rio de Janeiro: Campus, 1999.

CASTRO, Celso. (Org.) Evolucionismo cultural: textos de Morgan, Tylor e Frazer. Rio de Janeiro: Jorge Zahar Ed., 2005.

CASTRO, Cláudio de M. O tempo do desenvolvimento. Veja On-line, 1846, mar 2004. Disponível em: <http://veja.abril.com.br/240304/ponto de vista.html>. Acesso em: 20 jul 2004.

DAMATTA, Roberto. Conta de mentiroso: sete ensaios de antropologia brasileira. Rio de Janeiro: Rocco, 1993.

ELIAS, Norbert. Sobre o tempo. Rio de Janeiro: Jorge Zahar Ed., 1998.

EVANS-PRITCHARD, Edward. E. Os nuer. São Paulo: Perspectiva, 1978. HAASTRUP, Kirsten; VIBERG, Ake. Perspectives on lexical acquisition in a second language. Lund, Suécia: Lund University Press, 1998.

HALL, Edward. T. The power of hidden differences. In: BENNETT, Milton. J. (Ed.) Basic concepts of intercultural communication. Yarmouth, EUA: Intercultural Press, 1993.

- A dança da vida: a outra dimensão do tempo. Lisboa: Relógio D’Água Editores, 1996. 
HARRISON, Phyllis. A. Behaving Brazilian. Rowley, EUA: Newbury House, 1983.

JANGADA BRASIL. Como vovó dizia: a sabedoria popular dos provérbios. (1998) Disponível em: <http://www.jangadabrasil.com.br/proverbios/ pesquisa.asp >. Acesso em: $10 \mathrm{dez} .2010$.

LEVINE, Robert. A geography of time. New York, EUA: Basic Books, 1997.

NATTINGER, James. R.; DeCARRICO, Jeanette. S. Lexical phrases and language teaching. Oxford: University Press, 1992.

NOVAES, William. Trânsito de SP já não ajuda quem cedo madruga. O Globo, 07 abr. 2009. Disponível em: < http://extra.globo.com/noticias/ brasil/transito-de-sp-ja-nao-ajuda-quem-cedo-madruga-263207. html\#ixzz1b8SdCUje>. Acesso em: 30 maio 2009.

NUNES, Benedito. O tempo na narrativa. São Paulo: Ática, 1995.

OLIVEIRA, Jaqueline. Brazil: a guide for businesspeople. Yarmouth, Canadá: Intercultural Press, 2001.

ORTÍZ ALVAREZ, M. L. Expressões idiomáticas: ensinar como palavras, ensinar como cultura. In: PINTO, Paulo F.; JÚDICE, Norimar. (Org.). Para acabar de vez com Tordesilhas. Lisboa: Colibri/APP/SIPLE, 1998.

PERGUNTAS CRETINAS. Dicionário Brasileiro de Ditados Populares. (2006)_Disponível em: <http://www.perguntascretinas.com.br/dicionariobrasileiro-de-ditados-populares-novo $>$. Acesso em: 10 dez. 2010.

PONTES, Eunice. Espaço e tempo na lingua portuguesa. Campinas: Pontes, 1992.

PORTAL BRASIL. Adágio brasileiro (dito popular). 2001. Disponível em: $<$ http://www.portalbrasil.net/ditopopular/t.htm $>$. Acesso em: 10 dez. 2010. SILVA, José. P. Ensaios de Fraseologia. Rio de Janeiro: CiFEFiL/Dialogarts, 1999.

SHIRTS, Matthew. A diferença entre a noite e o dia. O Estado de S. Paulo, Caderno 2,12 de abril de 2004. 
STEWART, Edward. C.; BENNETT, Milton. J. American cultural patterns. In: A cross-cultural perspective (revised edition). Yarmouth, Canadá: Intercultural Press, 1991.

TAGNIN, Stella. O. Expressões idiomáticas e convencionais. São Paulo: Ática, 1989.

THOMPSON, Edward. P. Costumes em comum: estudos sobre a cultura popular tradicional. São Paulo: Companhia das Letras, 1998.

TITONE, Debra. A.; CONNINE, Cynthia. M. On the compositional and noncompositional nature of idiomatic expressions. Journal of Pragmatics, 1999.

TORRES-DOS-SANTOS, Danúsia. Tempo intercultural: o conceito de pontualidade na cultura brasileira e o ensino/aprendizagem de PL2E. 2007. 181f. Tese (Doutorado em Estudos da Linguagem) - Departamento de Letras, PUC-Rio, Rio de Janeiro, 2007.

TORRES-DOS-SANTOS, Danúsia; MEYER, Rosa M. B. Aspectos da identidade temporal brasileira. In: MEYER, Rosa. M. B.; REBELO, Ida M. M. (Orgs.) Português para estrangeiros: territórios e fronteiras: entre a área de estudos e pesquisa e a prática profissional cotidiana. Rio de Janeiro: PUC-Rio, 2008. Disponível em: $\leq$ http://www.letras.puc-rio.br/ Publicacoes/ccci/artigos.html . Acesso em: 25 maio 2010.

XIDIEH, Owaldo E. Anexins em contramão. Estudos Avançados, v. 13, São Paulo, 1999. Disponível em: < http://dx.doi.org/10.1590/S010340141999000100019>. Acesso em: 10 dez. 2010. 